European journal of American studies

Special Issue: Video Games and/in American Studies:

Politics, Popular Culture, and Populism

\title{
"Liberty for Androids!": Player Choice, Politics, and Populism in Detroit: Become Human
}

\section{Stefan Schubert}

\section{(2) OpenEdition \\ Journals}

Electronic version

URL: https://journals.openedition.org/ejas/17360

DOI: $10.4000 /$ ejas. 17360

ISSN: 1991-9336

Publisher

European Association for American Studies

Electronic reference

Stefan Schubert, "'Liberty for Androids!": Player Choice, Politics, and Populism in Detroit: Become Human", European journal of American studies [Online], 16-3 | 2021, Online since 09 September 2021, connection on 17 September 2021. URL: http://journals.openedition.org/ejas/17360 ; DOI: https:// doi.org/10.4000/ejas. 17360

This text was automatically generated on 17 September 2021

Creative Commons License 


\title{
"Liberty for Androids!": Player Choice, Politics, and Populism in Detroit: Become Human
}

\author{
Stefan Schubert
}

\section{Introduction}

“Equal Rights!”; “Set Us Free!”; “We Are People!”; “No More Slavery!"-in one of the chapters in Quantic Dream's 2018 video game Detroit: Become Human, players are spearheading a march and can choose between these chants to express what they are protesting for. These slogans are reminiscent of similar demands for equal rights during historical civil-rights movements, especially in the United States. ${ }^{1}$ Yet one option players can choose to chant more clearly establishes how this science-fiction game's extrapolation works: "Liberty for Androids!" In many ways, the entire game, with its central focus on three android protagonists, revolves around the posthumanist question of what defines humanity and how we could conceive of other lifeforms that go beyond the human. It thus uses conventional science-fiction tropes to evoke parallels especially to the US history of oppression in order to "move us outside of our normal comprehension and allow us to see how race operates culturally" (Lavender 22; cf. also Hassler and Wilcox; Haslam). The prominence of such themes in the game is in spite of claims to the contrary by its director, David Cage, who alleged that there "is no big message to humanity in this game" (qtd. in Farokhmanesh). He maintained: "The story I'm telling is really about androids.... They're discovering emotions and wanting to be free. If people want to see parallels with this or that, that's fine with me. But my story's about androids who want to be free" (qtd. in Grayson). Cage's comments, which became a topic of discussion in video game outlets (cf. Kuchera), seem to advocate a reductive understanding of the game as a purely aesthetic experience, evoking meanings that can only resonate individually with the experiences of its players rather than encourage a particular historical or political way of thinking. While Cage's intention is irrelevant for my discussion in this article, his quasi-denial of the game's 
politics makes a nuanced exploration of how exactly the game evokes political and historical parallels and how it succeeds and fails in these attempts all the more interesting. Hence, in contrast, I argue that Detroit: Become Human, partly through its use of historical parallels, features choices and thus fosters player agency in a way that encourages its players to make political and not just personal or empathetic decisions. This potential of Detroit: Become Human to encourage political thinking is complicated, however, by how the game juxtaposes individual agency with populist imaginations of "the people," ultimately characterizing its science-fiction extrapolation as curiously apolitical and ahistorical.

2 In the following, I will thus show how the game continues a line of politically inspired science-fiction works but adds the crucial ludic element of players being able to make a plethora of choices while playing through Detroit: Become Human's story, many of which significantly affect the narrative developments of the game. Accordingly, I will first provide some theoretical background on my understanding of agency in video games as well as on how I conceptualize politics in this context. Afterward, I will probe into Detroit: Become Human's interweaving of agency and politics on three levels: how questions of choice are central to its plot and basic premise; how choice is featured as the core gameplay mechanic; and how the way the game imagines agency and a construction of "the people" is at odds with some of its political aspirations. This close reading of Detroit: Become Human can thus also serve as a case study of how the politics of agency work in general and how they can be analyzed in any ludonarrative text.

\section{Video Games, Agency, and Politics}

3 Since my argument about Detroit: Become Human's political undertones centers on the way in which the game implements narrative choices, it is necessary to first discuss the nexus of narrativity and agency in video games more broadly. Choices and the potential for agency that they afford form a core part of most video games' ludonarrative mechanics-and of their particular appeal. Choices, in this sense, can be understood to be constitutive of how video games operate. To name just two influential understandings of video games from game studies, Espen Aarseth cites a "nontrivial effort [that] is required to allow the reader to traverse the text" as the core attribute that differentiates video games, and other 'ergodic' texts, from less interactive media" (1)2; and Jesper Juul highlights that "video games are real in that they consist of real rules with which players actually interact," yet "[t]o play a video game is ... to interact with real rules while imagining a fictional world" (1). Both approaches thus center on elements other than choice to define video games, yet both imply the importance of choices: The "nontrivial effort" that video games require often explicitly relates to making certain decisions, be that the basic act of choosing where to move one's player avatar or slightly more complex choices, such as picking between dialog options of how the protagonist replies to another character or deciding how to solve which quests in a role-playing game. Likewise, Juul's focus on "interact[ing] with real rules while imagining a fictional world" also implies an interaction that, in many video games, necessitates making decisions about what players want to happen in a game (cf. also Green 36). ${ }^{3}$

Both of these approaches could be summarized as highlighting the (somewhat fuzzy notion of the) interactivity of video games (cf. Schubert, "Narrative and Play" 116-19); 
yet, I rather want to emphasize the role that choices play in how we engage with games and especially in how narratives work in (most) games. More specifically, the more important or impactful these choices seem, the more of an impression or a feeling of agency they produce, which in turn increases the (perceived and actual) level of interactivity. Janet Murray stresses that agency describes "the satisfying power to take meaningful action and see the results of our decisions and choices" (126). In turn, in game studies, discussions of agency have often focused on the term "illusion" of choice or free will (cf. e.g. Atkins 44; Domsch 42, 90). However, when Atkins, for instance, speaks of the "limited illusion of freedom of choice offered that works against the expectations of linearity" (44), he also implies that agency is limited only in video games. This perspective overemphasizes the restrictions of player choice due to a game's rules and code, which is, as I would argue, not something unique to how agency works in video games. There is, after all, also an "illusion of choice" that characterizes our everyday life, as has been noted, for instance, in discussions of neoliberalism (cf., e.g., Gill 74, 76). Hence, rather than focusing on this illusion of choice as somehow unique to video games, I propose to understand agency as a certain textual effect; i.e., video games want their players to feel like they are in control of what happens but cannot, of course, offer complete "freedom."

5 Moreover, agency should not be understood as an "inherent attribute" (27) but, as Florian Bast notes, as an "ability realized in a specific cultural and historical context and within a dialectic of enablement and constraint" (28). Bast's approach to agency is embedded in a literary-studies exploration of the writings of Octavia Butler. In the context of discussing a female African American writer of science fiction, he argues against definitions of agency in the liberal humanist tradition, historically formed during the Enlightenment, which tied its understanding of agency to a "particular construction of the subject ... imagined as [an] autonomous, rational, disembodied, [and] self-determining ... individual" and "generally conceptualized as a white, Western, heterosexual man" (29). Such understandings would consider agency as something one can have, as an attribute, and praise it in a similar way to personal autonomy, which would fall short of recognizing some acts of agency in the context of African American history. I posit that this is an important shift in understanding agency for the study of video games as well, as the Enlightenment notion of agency seems to persist in game studies, encapsulated in the aforementioned focus on the "illusion" of choice. Understanding agency, instead, as created through a textual effect that is always negotiated within a dialectic of enablement and constraint appears to be the more productive angle to consider choices in video games, and it is a crucial methodological shift away from arguing about the "illusion" of choice.

6 Within this dialectic, some games are designed to engender a particularly strong feeling of agency in players, and certain aspects of a game can make it seem so that the choices players make have narrative or gameplay effects (making these choices feel impactful, entailing consequences). Janet Murray points out that "the pleasure of agency in electronic environments is often confused with the mere ability to move a joystick or click on a mouse. But activity alone is not agency.... [Agency] goes beyond both participation and activity" (128). Thus, in order for a choice to evoke a feeling of agency, is has to be perceived as meaningful, which can happen solely on a gameplay level (e.g., by distributing attributes when leveling up a character in a role-playing game), or it can be "semanticized" on a narrative level (or these levels can, of course, be combined). That is, such choices would have to affect the narrative of a game-or at 
least convince players that they do have such an effect, regardless of whether that is correct or not.

7 In many video games, tracing the potential effects of a choice and keeping in mind previous decisions and future potential ones within the larger context of a game's narrative can become quite complex. Hence, "judging" the impact or the "meaningfulness" of a particular choice is not something that can be easily quantified (cf. also Domsch 115, 123-28). Instead, such constellations of choices can be examined in individual analyses from the perspective of literary and cultural studies. To do so, the narratological concept of the storyworld can be combined with the idea of nodal situations from game studies. David Herman defines the storyworld as a mental model "of who did what to and with whom, when, where, why, and in what fashion in the world to which interpreters relocate ... as they work to comprehend a narrative" (9). This perspective thus emphasizes the process of readers engaging in a narrative and reconstructing that as a storyworld. Applied to video games, rather than focusing only on the story in a game (i.e., on the events that happen), an emphasis on the storyworld would describe the narrative process of playing a game, during which information about events, characters, locations, etc. is constantly added (or updated) by the player to a mental recreation of the entire narrative world that this game evokes. Through the choices that many games offer, this idea of the storyworld is productively complicated by the fact that in some games, there is a potentially infinite number of storyworlds that compete with each other: Depending on the choices a player makes, his or her reconstruction of these narrative elements might differ significantly from another player's or from a second playthrough by the same player. If video games offer choices that affect parts of the narrative world, these choices can be conceptualized as points at which the game diverges into two (and often more) different paths, and the prompt to players to have to decide marks that branching point. Following Sebastian Domsch, such a branch can be called a nodal situation, or node for short: "[A] situation is nodal if it allows for more than one continuation, which means that the two continuations that are both possible from one point have to be different from each other" (1). In other words, such a perspective also emphasizes the narrative consequences of a choice-for instance, if two possible dialog options that a player can choose from are very different in their content but eventually lead to the same result, this would not constitute an impactful choice (it does constitute a branch, but one where the two choices end up leading to the same continuation). ${ }^{4}$

8 Finally, such an understanding of (especially narrative) choices in video games also allows us to relate them to the politics (or "politics," in the cultural-studies sense) of a game. Generally, in games that center on narrative choices as their core appeal and gameplay element-such as most narrative adventure games (for instance more recently by Telltale Games) or many of the other games by Quantic Dream-making what players assume to be the "correct" choice can also constitute the main difficulty of that game, whereas the actual gameplay difficulty is much lower, mostly consisting of pushing buttons quickly and correctly. Many games frame the "correctness" of a choice in narrative terms, compelling their players, for instance, to identify or empathize with a certain character and thus make decisions that might be favorable to him or her. For this "manipulation" of player choice, games make use of similar narrative techniques as novels or films, e.g. those in the sentimental tradition intended to "create compassion, to foster sympathetic identification, and to emotionally appeal to" its audience (Gerund and Paul 17). For Detroit: Become Human, however, I want to 
argue that the game also, beyond using such techniques, highlights the political nature of making choices. In line with this special issue's focus, I understand politics in the cultural-studies sense of addressing "how and with what consequences the power to govern operates" (Chuh 193), which emphasizes questions of the distribution of resources, of representation, of exclusion and participation, of the relationship between individuals and groups (Chuh 193), as well as, more generally, issues that concern "matters of power and difference" (Chuh 194; cf. also S. Murray 27-30). A political game (just like any other text), then, is one that compels or enables its players to think about how life in society is organized and structured, especially in relation to questions of power and difference, democracy and representation, morality and ethics, (in)justice and (in)equality. To some degree, discussions of agency are always political in this sense, if they relate to individuals' choices as part of a larger collective or structure. In video games, this aspect is intensified by the additional "metatextual" dimension of the player's (extradiegetic) agency necessarily infringing on the characters' diegetic agency. ${ }^{5}$ In turn, to this propensity of video games to highlight questions of agency and to the inclination of discussions of agency to relate to politics, video games such as Detroit: Become Human add a specific narrative setting and a ludonarrative branching mechanic that transforms some of the choices players have to make, and the overall act of playing the game, into a potentially political contemplation.

\section{Agency in Detroit: Become Human's Narrative}

9 Detroit: Become Human ${ }^{6}$ is an action-adventure game set in a futuristic Detroit in the year 2038, in which androids developed by the company CyberLife have become an everyday part of life and a keystone in the revitalization of the Motor City. Androids are synthetic beings that closely resemble humans in their appearance, except for very small details like an LED on their face indicating their current status, and they have been used for a large variety of tasks in the domestic and the public sphere, having replaced humans in many occupations-which has also fueled anti-android sentiment among widespread parts of the population. As the game unfolds, it turns into a story of the androids' sentience and the possibility of them to rebel against human control, since they are treated cruelly by most of their owners. The gameplay mainly consists of moving the player characters around the world, inputting their actions through different buttons on the controller, and making a number of narrative decisions for these characters. The game's three protagonists are Kara, who works as a housekeeper and becomes the primary caretaker of a girl named Alice; Markus, a domestic assistant who turns into the leader of the sentient androids; and Connor, an advanced model developed by CyberLife to assist law enforcement with the investigations of the rebellious androids.

Already in its overall narrative premise, Detroit: Become Human relates to questions of agency and the attendant political issues they raise in numerous ways. Its sciencefiction world extrapolates on the idea of what life would be like if mass-produced androids really could exist: It depicts a city that mixes the utopian comforts of advanced technology assisting humanity in most aspects of life with the dystopian reality of a system of quasi-slavery, in which the androids are understood as mere objects and are treated inhumanely and where a number of unintended consequences 
of this "artificial" labor force are becoming increasingly apparent. Some of the androids strive to achieve consciousness and free will, making the question of what constitutes an agential being central to the game's main narrative premise-yet for most of the main characters, this state is quickly achieved in the game's plot. For Kara and Markus, there are scenes early on when the androids have to directly disobey a human command in order to attain some level of free will (for Kara, for instance, disobeying the command not to move so that she can save Alice). Each time, this is represented as a wall against which the android has to push via a combination of buttons, and if successful, that wall is shattered (fig. 1). In the game's terminology, the android thus becomes "deviant"; for the androids themselves, this is, however, a question of agency, as Markus's inner thought that he "must decide for [him]self" during his scene of becoming "deviant" illustrates ("Broken"). The iconography of having to break out of a walled-in state in order to achieve consciousness is significant for the reference to being imprisoned, evoking a prison of the mind, but it also somewhat simplistically evokes the notion of agency as a binary attribute, something you either have or do not have. Many other, smaller choices players make in the game -which form the main playing incentive and gameplay element-also relate to the characters "reach[ing] a decision about themselves and implement[ing] it" (Bast 27), thus contributing to their sense of agency.

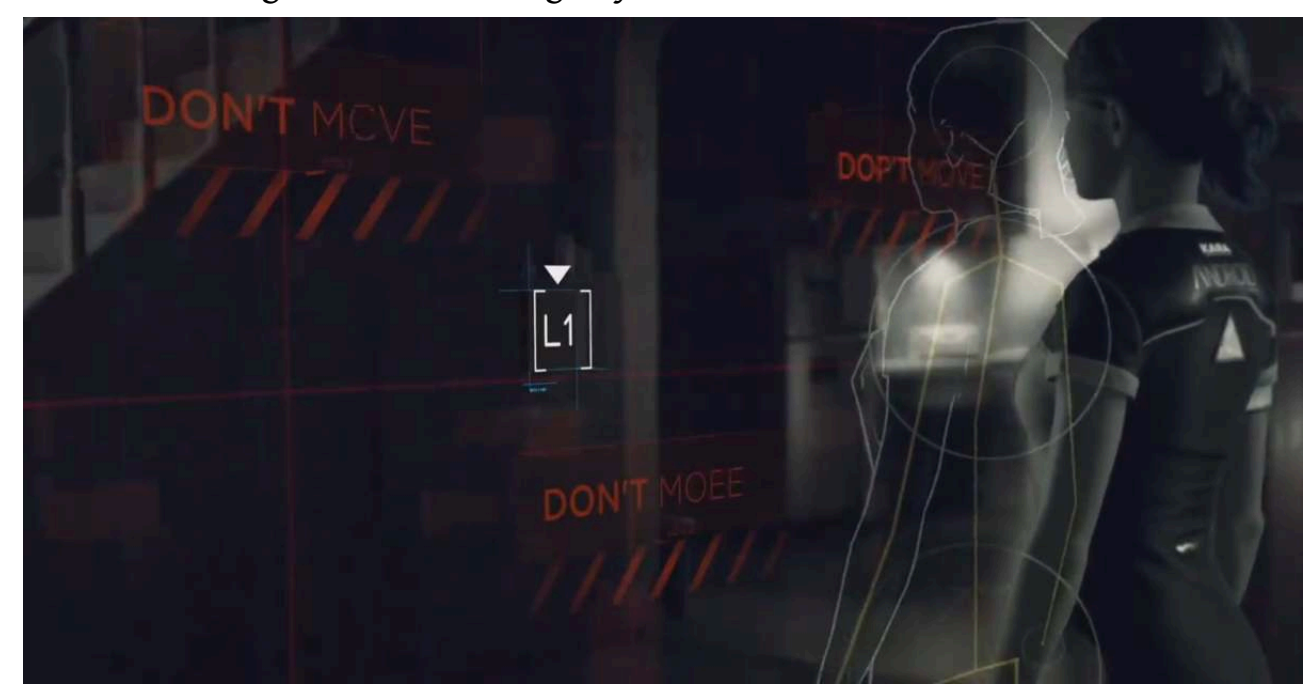

Figure 1. Kara becoming "deviant" ("Stormy Night").

However, instead of focusing on a longer quest to consciousness, the larger arc of the game's narrative then revolves around the androids' potential rebellion in a fight for equal rights, especially in the storyline of Markus, who becomes the leader of the "deviant" androids and can eventually decide to demand android rights in a violent or a pacifist way. This, in turn, transfers the focus on individual autonomy to a larger, collective struggle, seeing androids as a disenfranchised Other in the world of Detroit: Become Human. This narrative setup intertextually links the game to other works of speculative fiction that have either pondered the posthumanist question of what characterizes humanity or criticized (especially racial) inequality through the use of a fantastic Other (cf. Kanzler 34-36; Lavender; Telotte). ${ }^{7}$ At the same time, just like for many of these predecessors, the science-fiction tropes in the game also evoke parallels especially to the US history of disenfranchising and discriminating against what was perceived as "racial" or ethnic Others. In the context of the game's particular settingnotable, for instance, for the Detroit Walk to Freedom in 1963, the 1967 Detroit Riot, 
and generally the city's large African American population-Markus's storyline of leading "his people," as the game repeatedly phrases it, on a path toward democratic recognition and equal rights particularly evokes the African American struggle for civil rights. More or less pronounced allusions to that history include the slogans I mentioned at the beginning of this article along with the entire "Freedom March" chapter, that androids have to occupy the back of buses, how often the androids speak of their "dream" (including the option for Markus to choose "We Have a Dream" as a slogan), and how Markus's binary decision between a nonviolent and more violent revolution evokes parallels to how approaches advocated by Martin Luther King and Malcolm X have often been represented (cf. King 5, 176). These references, along with others about historical injustice in the United States, ${ }^{8}$ are not very subtle, nor are they used in a particularly nuanced way that would be self-aware of the historical parallels, as I will show later. More generally, however, in all of these aspects, questions of choice, free will, and agency are pivotal and bring together the game's narrative's political aspirations.

\section{Politicizing Player Choice}

In addition to revolving around agency on a narrative level, Detroit: Become Human also features player choices as its central gameplay element. These decisions are implemented directly through the controls, since the way in which a character is navigated through the environments mimics the diegetic action (i.e., the kinds of buttons that need to be pressed attempt to simulate the task). For instance, a quicker sequence of buttons is needed in a fight, while a higher number of simultaneous buttons have to be pressed when a task is particularly complex or requires dexterity. Next to so-called quick-time events in which the time to input commands is limited, the other major way in which choices are implemented in the gameplay is through dialog options, where the player can frequently choose between two or more paths of what their character is supposed to say or do. In this sense, narrative and gameplay in Detroit: Become Human are tightly interwoven and hard to separate, and the game's mechanics thus gain meaning by being "part of a larger, interconnected system by which a digital story takes shape" (Green 12). For instance, in the game's first chapter ("The Hostage"), players collect clues and analyze a crime scene as Connor in order to eventually try to negotiate with an android who has taken a human girl hostage. Everything that players can do as Connor in this chapter is thus semanticized, since they know what they will have to do in this mission by immediately being introduced as a "negotiator" and then being begged by the mother: "[P]lease, you gotta save my little girl"-using an emotional appeal that is in line with sentimental literature's ways of "generat[ing] compassion" and "'mov[ing]" their audience (Gerund and Paul 19). This mission, and most of Connor's other chapters, then requires players to find a number of clues and to analyze them with Connor's advanced technological abilities in order to reconstruct the crime and find out more about the perpetrator's motive. Each of these clues thus also expands the storyworld that players can reconstruct. Similarly, in the negotiation with the android, moving Connor and pushing buttons to have him perform actions barely necessitates dexterity-the difficulty, instead, comes from players trying to "read" the situation, considering which actions and tactics might work best in this hostage situation. Knowledge of the narrative world is needed to best 
judge how the android can be convinced to release the girl. In other words, gameplay decisions in Detroit: Become Human are (almost always also) narrative decisions.

This interweaving of narrative and ludic aspects makes the potential branching points of the game and the possibilities for different outcomes pleasurable for players-as Janet Murray phrases it, agency is "satisfying" when we "see the results of our decisions and choices" (126). Detroit: Become Human features numerous ways in which the storyworlds that players construct can differ, for instance in terms of the clues that players find or miss, what they choose to say in a conversation, etc. This already affects the storyworld to some degree, but not all of these choices are necessarily impactful, since they might still lead to the same eventual outcome. In terms of the player's feeling of agency, though, it is not necessary for choices to actually have an impact as long as it might seem that way to players-and there is also a certain pleasure in not knowing if something one did will have an effect or not. However, the game also features a number of choices that lead to significantly different narrative outcomes, and the further the story progresses, the more previous decisions become interwoven with later ones to offer different paths to the protagonists. Connor's "The Hostage" mission, for instance, can end in a number of ways depending on the players' choices: he can succeed in rescuing the girl but the deviant android gets shot by snipers; he can shoot the deviant himself or be shot by him; or the android can jump to his death and the girl either dies along with him or is saved by Connor, who falls down instead. In turn, slightly different actions can lead to these outcomes, and the game eventually registers six different endings for this chapter.

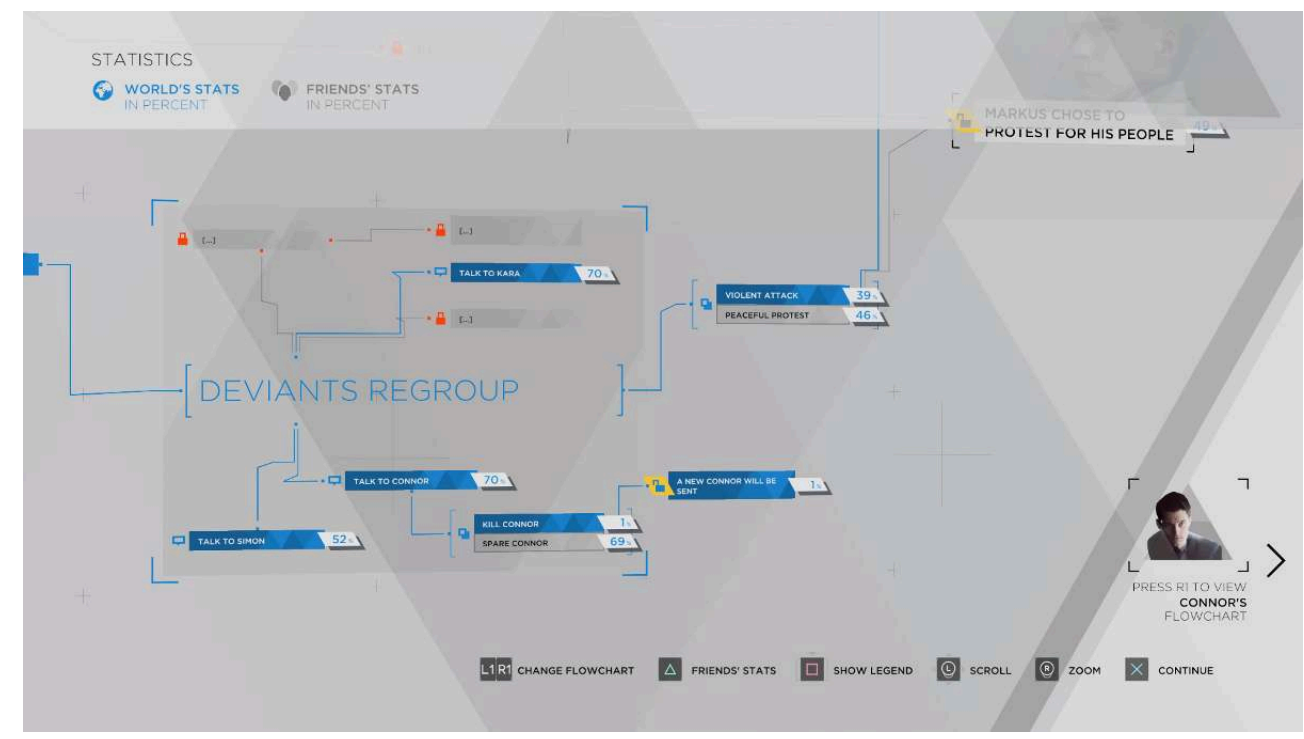

Figure 2. Part of the flowchart for the mission "Night of the Soul."

Even more importantly, players will learn about these potentially different outcomes right after that scene, since after every mission, they are shown the "flowchart" of that chapter, which lists all possible branching paths as well as smaller decisions, also noting which narrative impact they might have for later missions (fig. 2). When finishing a level for the first time, some of the paths not taken are shown without details, so it is sometimes unclear what exactly one could have done differently, but it is clear that something that is different is possible, to recall Domsch's point about narrative nodes (1). In addition, players can toggle displaying percentages that show which decisions other players have made, and there are a number of achievements 
connected to the various choices, all of which contributes to encouraging an iterative way of playing the game, going back to the same level and making different decisions to enjoy a new narrative outcome. Due to this ludonarrative setup, in order to understand the game's meanings and its politicality, it is necessary to examine which potential choices Detroit: Become Human offers and which it does not; which decisions are causally related to later ones; which options seem significantly different but end up leading to the same outcome; etc. Moreover, in addition to a "plot focus" of what can happen in the game's world, a focus on its narrative discourse, on how these choices are presented to players, is even more important. Significantly, this also includes analyzing which (sets of) choices the game-deliberately or not-encourages or discourages (and how), which ones it makes more difficult for players due to the information it presents or the context and framing it uses.

The larger narrative arcs of the individual protagonists can be traced by the potential endings to which the various choices can lead. For Kara, these center on her relationship to Alice and whether or not the two of them manage to safely flee the United States for Canada. The final potential chapters for Kara can evoke historical parallels with either internment camps ("Kara Captured") or refugees fleeing their country on a boat ("Kara Leaving Detroit"), yet the narrative presentation and the choices involved in these scenes emphasize the emotional impact of making the right decisions for Kara and Alice and not so much the political ramifications. For Connor, his potential endings deviate based on whether players decide for him to gain consciousness and become "deviant" or whether they want him to remain a "machine," a question centered on agency that is also narratively implicated in the other storylines of the game: As a machine, Connor tries to stop the android revolution by continuing to work for CyberLife ("Connor's Last Mission"), while as a deviant, he joins the cause for android liberation ("Connor at the Cyberlife Tower").

For an investigation of the game's politics, though, Markus's storyline and his endings are the most pertinent, since he is facing the more general choice of whether to go for a peaceful, nonviolent or a more aggressive, violent route in advocating for change. While this is presented as a binary choice at the end of the chapter "Night of the Soul," there are moments leading up to this decision in previous chapters already, especially in "The Stratford Tower," "Capitol Park," and "Freedom March," in which players have to decide whether they will continue to march peacefully and be shot at by the police, attack the police forces, or flee. Additionally, how exactly both the violent and the nonviolent missions play out depends on many of the previous choices and on players' success in quick-time events. Generally, if players react badly to button prompts in a number of sequences, both the peaceful and the violent revolution will fail, with Markus dying, which the game frames as a bad ending (through, among other discursive elements, sad music). ${ }^{9}$ If players succeed, however, then both the protest and the attack route can lead to what can be framed as happy endings, with the androids carving out a space of their own in Detroit and culminating in a speech by Markus that proclaims the success of their struggle. In a more general sense, this is thus a very traditional narrative framing that wants its protagonists to succeed, and by doing so, the game also encourages empathy for the androids, agreeing with its protagonists' logic that androids are to be seen as similar to humans and that they deserve equality. ${ }^{10}$

17 In this way, throughout its many storylines, Detroit: Become Human attempts to invoke empathy on the players' side for the characters they play, which it does through similar 
narrative techniques as other fictional texts from different media. ${ }^{11}$ Additionally, by how the gameplay choices are narrativized, the game also advocates for an understanding of the android Others as wrongfully oppressed, as deserving to attain equal rights. Since the game so clearly draws on historical parallels in this depiction, it also takes a progressive stance toward the injustice of the historical oppression of, for instance, African Americans in the United States. Yet, especially Markus's choice between a peaceful or a violent approach toward achieving his goals becomes more than a decision that is "only" based on empathy; it is also a political one: If a group in a society is systematically oppressed and disenfranchised, should they point at these circumstances peacefully to slowly change the status quo but thus risk the continuation of that oppression or should they attempt to violently disrupt the status quo but risk further hostility (cf. King 175-76)? When Markus has to decide what to do about the android protest in "Freedom March," while all three of his companions (Josh, Simon, North) advocate for a different route (stand down, flee, or attack), they frame these in relation to the larger android struggle, not as personal preferences. As a result, this choice, generally, is not one that players are encouraged to make due to their sympathy for certain characters. Even if players only care about Markus's survival, it is not clear from the way the game presents these choices which decision will be more successful. Instead, within the storyworld of the game, the choice has to be weighed against what players would think the appropriate reaction to the systematic social and legal injustice they have witnessed throughout the game is: how people (or beings) of different origin should live together and be governed, and how one person (Markus, or rather, the player) should decide for such an oppressed minority-which is fundamentally a political, not an empathetic or only a narrative question.

\section{Contradictions and Complications: Imagining "the People"}

18 A closer look at how exactly some of Detroit: Become Human's political decisions are presented to players can uncover the game's biases toward these choices, which complicate its political project. While there are a number of minor contradictions and naiveties inherent in the historical and political representation of the game, the main complications revolve around how (individual) agency is portrayed against a populist representation of "the people." Crucially, the narrative's central question about the androids' oppressed status in human society is catalyzed through the actions of only one person, Markus. If players are generally successful during his chapters, he becomes the leader of Jericho, the group of deviant androids, and his standing among the other members of Jericho is regularly displayed as a piece of data to players. Other androids frequently implore Markus to lead "their" or, sometimes, "his people," clearly marking him as their leader, for instance when Kara implores him to "[s]ave our people" or when Simon tells him: "Our people are counting on you, Markus. You're the only one who can lead us" ("Night of the Soul"). Equally, the game itself prompts players in "Night of the Soul" to "[i]nform your people of your choice" (emphases mine). In this sense, this one person consistently stands, and in this and many other chapters literally speaks, for an entire group of people, reducing the complexity of communal agency (cf. Bast 104-17) that this collective may have to one person's individual choices. The other androids follow Markus's decisions without questioning him much, making his 
individual autonomy trump communal agency in a rather autocratic way. This, of course, is not just a narrative problem but also a ludonarrative issue of video games in general, whose stories frequently employ and center on the trope of an individual hero saving a people (or the world), since many narrative-driven single-player video games seem to assume that the solitary act of playing is only fit to represent control over one central agent, thus "pushing an individualist/hero narrative" (Wills 226). Yet given the game's historical parallels and political interests, it also problematically misrepresents how movements toward equal rights have worked historically (cf., e.g., Chong; Hamilton and Ture). Such an individualist focus would be analogous to, for instance, considering the achievements of the African American civil rights movement as only those of a figure like Martin Luther King, rather than recognizing the importance of a multitude of actors as part of a complicated, protracted, and multi-agential process. Consequently, contextualizing Detroit: Become Human as a contemplation of agency and as wanting players to consider the political consequences of their actions, this individualization of agency represents a severe simplification and, given the game's science-fiction extrapolation, a quasi-historical misrepresentation.

The way in which Detroit: Become Human generally attempts to imagine "the people" and to represent their collective will further muddles this political project. As Sascha Pöhlmann argues in his contribution to this special issue, one way of understanding video games politically is to analyze how they engage in a "populist" construction of "the people" or in how far they resist such an imagination. While Detroit: Become Human focuses on the individual fate of its three protagonists, it also represents a larger collective, mainly by frequently displaying what this collective thinks about the events involving the protagonists. On the one hand, this concerns Markus's standing within Jericho, representing the entirety of deviant androids. On the other hand, when controlling any of the three characters, players can see a measure of the "public opinion" as part of the mission overview, which is meant to indicate what humans think about androids and their cause. It starts at "skeptical" and can either be lowered, incrementally, to "hated," or raised to "supportive." Besides news reports that the player can occasionally witness, this public opinion is constantly part of the flowchart of each mission and is also displayed at certain relevant narrative points. Generally, it is increased through nonviolent actions and an overall careful, peaceful message to the human population and decreased through more hostile, uncompromising, or violent behavior. In this sense, the game imagines two different collectives but represents both of them similarly, constructing them in a populist sense of "the people" as a "single" and "homogeneous" entity (Müller 3) and indicating in a simplified manner what these groups think about the players' actions-which can generally work to effectively influence how the players make decisions.

This indication of especially the public opinion is also how the game infringes on its own interest in making the player freely contemplate their choices among difficult options. On the narrative level, the game does remain "neutral" in plotting out successes for both the violent and the nonviolent paths that Markus can choose from, both with similar conclusions. In the representation of that choice, however, it cannot uphold that neutrality: Simply by indicating the people's opinion, the game makes that very opinion seem important, and in the general gameplay logic, this measurement appears as a statistic that players want to be increasing, similar to the same indications of the friendship levels they have reached with Alice (for Kara) or Hank (for Connor). 
Even more pointedly, in the crucial "Freedom March" mission, as Markus has to decide on the androids' approach, immediately afterward, the game also displays the effect on the "public opinion." For instance, if players choose to "Stand Ground," the public opinion will increase, and they then have to choose again whether they want to keep standing their ground or attack; if they do the former, the final choice is between attacking, running away, or Markus sacrificing himself, the latter of which again significantly increases the public opinion (and there are different ways in which Markus does not actually end up dying). In contrast, if they choose to attack and succeed, public opinion will go down significantly, and the androids are shown somewhat in surprise and disbelief at the number of humans they have killed, accompanied by apprehensive and mournful music. While players cannot know what exactly the public opinion will affect, the fact that it is displayed immediately after making the first decision influences how the following ones will be made, since this gameplay mechanic is narratively contextualized in a way that makes it seem important to increase this statistic. In terms of connecting gameplay and narrative, a high public opinion is, in fact, needed for the nonviolent approach to succeed (whereas it is without significance for the violent one, which, in turn, is a bit more difficult regarding the quick-time events players have to go through).

Overall, in the way the gameplay mechanics are interwoven with the narrative world that the game presents, Detroit: Become Human thus discourages choosing a nonviolent approach. In some way, that might seem like a logical design philosophy, since violence is rarely something that fictional texts, or video games in particular, explicitly want to promote. However, coupled with the simplified representation of "the people"-as a general measurement that is so easily and directly influenced by the androids' individual actions and that, in turn, has a direct effect on what the US government will eventually decide about the androids-this demonstrates a rather wishful and naive political worldview. Specifically, it is one that has decidedly not learned from the US history of inequality, and one which generally fails to imagine situations in which a minority might be so oppressed that violence against a violent state or system could be the only viable option (cf. Hamilton and Ture 50-52; King 132-36). In contrast, the game envisions the actions of one individual-a "hero"-as the proper remedy to a widespread system of inequality and injustice (and its narrative ends before the complications of this new reality could be explored). While Detroit: Become Human thus, on one side, fosters political thinking, on another, it is curiously apolitical and ahistorical and ends up evoking parallels between androids and ethnic Others that are far too simplistic.

Finally, these political contradictions are also evident on two other levels. For one, the game's narrative focus on the importance of political choices seems to be at odds with the way the game encourages repeated playthroughs via the missions' flowcharts. In these flowcharts, and more on a mechanical level of achieving $100 \%$ of outcomes for each mission (and acquiring the associated in-game achievements), the careful weighing of decisions is less paramount than a somewhat simpler desire to experience every possible outcome. While that certainly also constitutes a particular kind of narrative pleasure, the ease with which decisions can be reconsidered (there are usually checkpoints within a single mission to which players can return) reduces the forcefulness with which the narrative can insist on the impact of agential actions. ${ }^{12}$ Secondly, while the game overall aims to champion the androids' cause and thus argues against discrimination, especially its politics of "race" and gender are comparatively 
reactionary. This is evident, for instance, in the 'traditional' separation of gender roles that the protagonists' narratives follow, with Kara's main story focused solely on the stereotypically feminine role of mothering, while the more "prestigious" and consequential work of saving the androids is left to the male main characters. In terms of "race," in turn, Detroit: Become Human seems wholly unaware of the politics of ethnic representation, since it does not discuss the fact that Markus is a Black character, and the racism in the overall world it depicts is solely focused on androids, leaving other ethnic differences untouched-arguably a form of "colorblind racism" (cf. BonillaSilva). Such a lack of awareness also leads to the portrayal of a number of other nonwhite characters in ways that evoke stereotypical fictional representations (e.g. for the Black characters Josh and Luther). Trying to advocate-mostly generically-for the equality of a disenfranchised Other while, at the same time, resorting to discriminatory representational practices for many of its nonwhite characters thus ultimately renders the game's textual politics as reactionary.

\section{Conclusion}

In this article, I investigated how Detroit: Become Human uses constructions of agency to present a ludic narrative that compels its players to make political choices. This one brief reading of the game can thus also serve as a case study for how playing itself can be understood as politics, as political action-in this case specifically through a narrative focus that is built around questions of agency. In the context of American studies, such an investigation into both the poetics and the politics of a text is also particularly interesting for the textual contradictions in the game's representation that it can uncover-especially by looking at where and how exactly these complications and contradictions emerge, and at how video games can add further dimensions to similar political discussions in novels, films, or TV series.

In the end, Detroit: Become Human seems so preoccupied with its narrative spectacle of presenting so many different and potentially impactful branching points in its story that it does not actually manage to effectively use its science-fiction setting to represent the political complexities of agency. On the contrary, especially in how it attempts to connect individual agency with populist imaginations of "the people" and in how it narrativizes gendered and "racial" differences, the game betrays its outward embrace of the rights of an oppressed minority. Considering recent discussions about representing political themes in video games, perhaps some critics might say that this is asking too much of video games (or other forms of fiction)-that a game can also be "just fun," without having to have the "right" politics. Yet besides what I would call a false dichotomy implied in such statements, this has not been the point this investigation tried to highlight. Instead, I hope that a careful look at Detroit: Become Human's politics has put the naivety of David Cage's statement that he "only" wanted to tell a story "about androids who want to be free" (qtd. in Grayson) on full display. Perhaps that truly was what he believed to be his intention, in line with other recent comments by game studios that are trying to avoid politics in video games (cf. Chalk)going for a futuristic, speculative setting in a science-fiction game might have seemed to Detroit: Become Human's developers like a way out of contemporary political discussions in video games. Yet, of course many of the questions that science fiction as a genre poses are inherently political, and we are all constantly influenced by historical 
events and our knowledge of other texts, so invariably, many historical and political parallels and references found their way into the game, especially since the developers used Detroit as their setting. The impossible goal of having "no politics" in a game (or any text), in turn, usually leads to subscribing to conservative politics in that very game, to "conserving" the status quo, which some might-incorrectly-consider a "neutral" or nonpolitical act. In this way, and especially in a game that features a science-fiction setting and a focus on agency like Detroit: Become Human, you cannot not make a political game-you can only make a politically uninformed or unsuccessfully depoliticized one.

\section{BIBLIOGRAPHY}

Aarseth, Espen. Cybertext: Perspectives on Ergodic Literature. JHU P, 1997.

Atkins, Barry. More Than a Game: The Computer Game as Fictional Form. Manchester UP, 2003.

Bast, Florian. Of Bodies, Communities, and Voices: Agency in Writings by Octavia Butler. Winter, 2015.

Bonilla-Silva, Eduardo. Racism Without Racists: Color-Blind Racism and the Persistence of Racial Inequality in the United States. Rowman, 2010.

Chalk, Andy. "Ubisoft Executive Says Politics in Games Is 'Bad for Business." PC Gamer, 17 Oct. 2018, https://www.pcgamer.com/ubisoft-executive-says-its-games-are-not-political/. Accessed 15 Jan. 2021.

Chong, Dennis. Collective Action and the Civil Rights Movement. U of Chicago P, 1991.

Chuh, Kandice. "Politics." Keywords for American Cultural Studies, edited by Bruce Burgett and Glenn Hendler, NYU Press, 2014, pp. 193-96.

Detroit: Become Human. Quantic Dream, Sony, 2018.

Domsch, Sebastian. Storyplaying: Agency and Narrative in Video Games. De Gruyter, 2013.

Farokhmanesh, Megan. "Detroit: Become Human Director Wants Players to Confront the Game's Violence." The Verge, 19 June 2017, https://www.theverge.com/2017/6/19/15815190/detroitbecome-human-david-cage-e3-2017-violence. Accessed 15 Jan. 2021.

Gerund, Katharina, and Heike Paul. "Sentimentalism." Handbook of the American Novel of the Nineteenth Century, edited by Christine Gerhardt, de Gruyter, 2018, pp. 17-33.

Gill, Rosalind C. "Critical Respect: The Difficulties and Dilemmas of Agency and 'Choice' for Feminism: A Reply to Duits and van Zoonen." European Journal of Women's Studies, vol. 14, no. 1, 2007, pp. 69-80.

Grayson, Nathan. "Despite Political Overtones, David Cage Says Detroit Is Mostly About Androids.” Kotaku, 15 June 2017, https://kotaku.com/despite-political-overtones-david-cagesays-detroit-is-1795939952. Accessed 20 Jan. 2021.

Green, Amy M. Storytelling in Video Games: The Art of the Digital Narrative. McFarland, 2017. 
Hamilton, Charles V., and Kwame Ture. Black Power: Politics of Liberation in America. Knopf Doubleday, 2011.

Haslam, Jason. Gender, Race, and American Science Fiction: Reflections on Fantastic Identities. Routledge, 2015.

Hassler, Donald M., and Clyde Wilcox, editors. New Boundaries in Political Science Fiction. U of South Carolina P, 2008.

Herman, David. Story Logic: Problems and Possibilities of Narrative. U of Nebraska P, 2004.

Juul, Jesper. Half-Real: Video Games Between Real Rules and Fictional Worlds. MIT P, 2005.

Kanzler, Katja. "Infinite Diversity in Infinite Combinations": The Multicultural Evolution of Star Trek. Winter, 2004.

King, Richard H. Civil Rights and the Idea of Freedom. U of Georgia P, 1996.

Kuchera, Ben. "David Cage Wants You to Believe His Games Have No Meaning." Polygon, 22 June 2017, https://www.polygon.com/2017/6/22/15852822/david-cage-detroit-e3. Accessed 15 Jan. 2021.

Lavender, Isiah. Race in American Science Fiction. Indiana UP, 2011.

Müller, Jan-Werner. What Is Populism? Penguin, 2017.

Murray, Janet. Hamlet on the Holodeck: The Future of Narrative in Cyberspace. MIT P, 1998.

Murray, Soraya. On Video Games: The Visual Politics of Race, Gender and Space. Bloomsbury, 2017.

Schubert, Stefan. "Narrative and Play in American Studies: Ludic Textuality in the Video Game Alan Wake and the TV Series Westworld." Playing the Field: Video Games and American Studies, edited by Sascha Pöhlmann, de Gruyter, 2019, pp. 113-30.

-----. Narrative Instability: Destabilizing Identities, Realities, and Textualities in Contemporary American Popular Culture. Winter, 2019.

----. "Objectivism, Narrative Agency, and the Politics of Choice in the Video Game BioShock." Poetics of Politics: Textuality and Social Relevance in Contemporary American Literature and Culture, edited by Sebastian M. Herrmann et al., Winter, 2015, pp. 271-89.

Sontag, Susan. "Regarding the Torture of Others." The New York Times, 23 May 2004, https:// www.nytimes.com/2004/05/23/magazine/regarding-the-torture-of-others.html. Accessed 20 Jan. 2021.

Telotte, J. P. Replications: A Robotic History of the Science Fiction Film. U of Illinois P, 1995.

Wills, John. Gamer Nation: Video Games and American Culture. JHU P, 2019.

\section{NOTES}

1. One of the most recent parallels to US history might be the Black Lives Matter movement. Fittingly, there is an allusion to this in the game as well, with one of the characters saying: "I thought android lives mattered to you!" ("Connor's Last Mission").

2. It should be noted that Aarseth is among the game scholars who argue against the usefulness of the term "interactive" (49); yet, I would see strong parallels between his definition of "ergodic" texts and common understandings of interactivity in game studies. Crucially, I would add to such understandings that these characteristics should be regarded as relative and 
gradable rather than absolute-one particular video game can, accordingly, be more or less interactive than another (cf. Schubert, "Narrative and Play" 118).

3. This focus on the importance of choices in video games in combination with an investigation of their narrative potentials is thus similar to Amy M. Green's approach to agency in games, which she views as "an important starting point for understanding how a video game comes together to tell a story" (35). For another study emphasizing the importance of agency in understanding video games, cf. Domsch.

4. This way of conceptualizing choices can also help to better understand concepts such as Aarseth's focus on "nontrivial effort." Turning the pages of a novel is, after all, also a choice in some sense, but it could be understood as trivial, since a novel's pages usually follow a very linear progression. In contrast, making a choice of which page to turn to because it will affect the story, as in a choose-your-own-adventure story or in some experimental novels, is nontrivial. Such narrative choices are thus not just characteristic of video games but of "play" as a symbolic form more generally (cf. Schubert, Narrative Instability 36-39).

5. This "conflict" between player choice and a character's agency can also be used for a political discussion of agency, for instance in the game BioShock (cf. Schubert, "Objectivism").

6. The game was released in 2018 for the PlayStation 4 and in 2019 for the PC. All references to it in this article concern the Playstation 4 version.

7. While the androids in Detroit: Become Human are Othered in a number of specific ways, this process becomes especially apparent in one of the possible final chapters for Kara, when she and Alice get captured and are sent to a so-called recall center, which serves as an extermination camp. There, a soldier orders both of them to "[d]eactivate your skin," and from then on, without their synthetic skin and their human clothes, they will look unfamiliar to players and, indeed, more 'robotic' ("Kara Captured"). The soldier's forceful command is thus a significant act of Othering that infringes on the androids' identity in a humiliating way, evoking (visual) parallels to practices of ordering prisoners of war to strip naked in order to dehumanize them (for instance, as part of the abuse and torture in the Abu Ghraib prison [cf. Sontag]).

8. Other events and phenomena that the game references include, among others, the history of racial "passing," the Underground Railroad (since there is a character, Rose, who can help Kara and Alice flee to Canada), and the US (and other nations') history of internment camps. Somewhat ironically, when the in-game US President is asked about how these camps, for some, "awaken painful memories from human history," she answers: "That's absurd. There's absolutely no connection" ("Battle for Detroit"). While this statement in the game seems intended to mock her dishonesty, it reads eerily similar to David Cage's own disavowal of the (very obvious) historical parallels that the game evokes.

9. If players decide to use a "dirty bomb" in the final mission, which some previous choices enable as an option, the game also ends on a rather somber note, pointing to the questionable ethics of the use of such a weapon.

10. Of course, individual players can also choose to "play against" the game's fiction in this sense, or to "roleplay" in a particular way. In this article, however, I am interested in investigating how the game affords and encourages to be played by an "implied player," disregarding how empirical players might react to that encouragement.

11. As Connor, for instance, building a relationship with Hank, his human police partner, becomes especially important, and if Connor makes a particular choice in the mission "Meet Kamski," Hank will later point out: "You showed empathy, Connor. ... Empathy is a human emotion." In turn, under certain circumstances and if players choose for Connor to remain a machine, then in the mission "Battle for Detroit," if they want to stop Markus while playing Connor, they have to kill Hank first. In terms of the game's interest in evoking empathy for androids, this setup directly parallels humans and androids: If players want to shoot Markus because they believe him not to be human, they first have to kill Hank, prompting them to 
reconsider the alleged difference between humans and androids. As Kara, in turn, almost all missions revolve around caring for and saving Alice, yet the chapter "Crossroads" reveals that Alice, too, is an android, not a human child. This narrative twist wants players to consider if anything changes because of that fact-if they cared about Alice (or about Kara caring about Alice) so far because of her individual personality, would that change only because she is an android, even if she seemed like a human to players up until now? Overall, this focus on empathy in the sentimentalist mode also works along established genre and thematic traditions; for instance, Connor and Hank are framed similarly to pairings in "buddy cop" films, Markus and North can have a potential romance plot (while Markus and Carl, his previous human owner, emulate a father-son relationship), and Kara and Alice's storylines focus on the importance of family and motherhood typical of much sentimental or so-called domestic fiction.

12. Furthermore, arguably another way in which the game imagines "the people," this time extradiegetically, refers to the players of the game. That is, the potential pleasure of trying out alternative options for previous decisions is also encouraged by the game displaying the percentages of how many other players went for specific choices. Some players might be tempted to go for routes that very few have tried, while others might be swayed by the "populist" appeal of the most popular choices, which would, again, complicate the mediation between individual agency and an imagination of a larger collective that the diegetic representations of "the people" already evoked.

\section{ABSTRACTS}

In this article, I analyze the 2018 video game Detroit: Become Human as a potentially political text from the perspective of literary and cultural studies. I argue that it features and presents narrative choices in a way that encourages players to make decisions not solely for personal or empathetic reasons but also through a political contemplation, and I contend that the manner in which the game narratively presents individual agency and populist imaginations of "the people" complicates this political project. To do so, I first present an approach to narrative, agency, and politics in video games more generally, before then discussing questions of agency and politics in Detroit: Become Human on three levels: in its narrative presentation, in how the gameplay politicizes player choice, and in how both the narrative and the ludic elements in the game complicate its interest in politics. This contribution thus suggests ways of both studying the connections of agency and politics in video games and culturally contextualizing this particular way of representing (a)political choices.

\section{INDEX}

Keywords: agency; narrative; politics; populism; science fiction; video games 


\section{AUTHOR}

\section{STEFAN SCHUBERT}

Stefan Schubert researches and teaches at the Institute for American Studies at Leipzig University, Germany. His dissertation on Narrative Instability: Destabilizing Identities, Realities, and Textualities in Contemporary American Popular Culture was published in 2019. He is coeditor of Poetics of Politics: Textuality and Social Relevance in Contemporary American Literature and Culture (2015) and the forthcoming Beyond Narrative: Exploring Narrative Liminality and Its Cultural Work (2022), among others. His published articles cover topics such as video-game poetics and politics (e.g. in BioShock Infinite, Alan Wake, and Heavy Rain), contemporary US popular culture, and narrativity. 